\title{
Changes in phenotype and differentiation potential of human mesenchymal stem cells aging in vitro
}

Yueh-Hsun Kevin Yang ${ }^{1 *}$ (D, Courtney R. Ogando ${ }^{2}$, Carmine Wang See ${ }^{2}$, Tsui-Yun Chang ${ }^{2}$ and Gilda A. Barabino ${ }^{3}$

\begin{abstract}
Background: Adult mesenchymal stem cells (MSCs) hold great promise for regenerative medicine because of their self-renewal, multipotency, and trophic and immunosuppressive effects. Due to the rareness and high heterogeneity of freshly isolated MSCs, extensive in-vitro passage is required to expand their populations prior to clinical use; however, senescence usually accompanies and can potentially affect MSC characteristics and functionality. Therefore, a thorough characterization of the variations in phenotype and differentiation potential of in-vitro aging MSCs must be sought.

Methods: Human bone marrow-derived MSCs were passaged in vitro and cultivated with either DMEM-based or aMEM-based expansion media. Cells were prepared for subculture every 10 days up to passage 8 and were analyzed for cell morphology, proliferative capacity, and surface marker expression at the end of each passage. The gene expression profile and adipogenic and osteogenic differentiation capability of MSCs at early (passage 4) and late (passage 8) passages were also evaluated.
\end{abstract}

Results: In-vitro aging MSCs gradually lost the typical fibroblast-like spindle shape, leading to elevated morphological abnormality and inhomogeneity. While the DMEM-based expansion medium better facilitated MSC proliferation in the early passages, the cell population doubling rate reduced over time in both DMEM and aMEM groups. CD146 expression decreased with increasing passage number only when MSCs were cultured under the DMEM-based condition. Senescence also resulted in MSCs with genetic instability, which was further regulated by the medium recipe. Regardless of the expansion condition, MSCs at both passages 4 and 8 could differentiate into adipocyte-like cells whereas osteogenesis of aged MSCs was significantly compromised. For osteogenic induction, use of the aMEM-based expansion medium yielded longer osteogenesis and better quality.

Conclusions: Human MSCs subjected to extensive in-vitro passage can undergo morphological, phenotypic, and genetic changes. These properties are also modulated by the medium composition employed to expand the cell populations. In addition, adipogenic potential may be better preserved over osteogenesis in aged MSCs, suggesting that MSCs at early passages must be used for osteogenic differentiation. The current study presents valuable information for future basic science research and clinical applications leading to the development of novel MSCbased therapeutic strategies for different diseases.

Keywords: Human mesenchymal stem cell, Aging, Morphology, Proliferation, Differentiation, Adipogenesis, Osteogenesis, CD106, CD146, Gene expression

\footnotetext{
* Correspondence: kyang@ccny.cuny.edu

'Department of Biomedical Engineering, The City University of New York the City College, 160 Convent Avenue, Steinman 581, New York, New York 10031, USA

Full list of author information is available at the end of the article
}

(c) The Author(s). 2018 Open Access This article is distributed under the terms of the Creative Commons Attribution 4.0 International License (http://creativecommons.org/licenses/by/4.0/), which permits unrestricted use, distribution, and reproduction in any medium, provided you give appropriate credit to the original author(s) and the source, provide a link to the Creative Commons license, and indicate if changes were made. The Creative Commons Public Domain Dedication waiver (http://creativecommons.org/publicdomain/zero/1.0/) applies to the data made available in this article, unless otherwise stated. 


\section{Background}

Mesenchymal stem cells (MSCs) that were initially described as colony-forming unit fibroblasts are uncommitted precursors of nonhematopoietic tissues and thus are able to give rise to several cell lineages of mesodermal origin, such as chondrocytes, osteoblasts, adipocytes, myocytes, cardiomyocytes, and tendon cells $[1,2]$. Although first identified in the bone marrow, spleen, and thymus of adult mice by Friedenstein et al. [3], MSCs have been extracted from many other sources including umbilical cord blood $[4,5]$, synovial membrane [6], adipose tissues [6, 7], skeletal muscle [8,9], and pancreas [10]. Among the different origins, however, bone marrow is still by far the best characterized source of MSCs due to a less invasive isolation procedure [11].

MSCs are an attractive candidate for use in regenerative medicine because of their potential for self-renewal and multipotency, as well as their trophic and immunosuppressive effects [11]. Hayflick reported that the proliferative capacity of MSCs was preserved after 27 years of cryogenic storage [12]. Clinically, MSCs have been used to improve the engraftment of hematopoietic stem cells (HSCs) post-transplantation [13] and to facilitate hematopoietic recovery from high-dose chemotherapy received by breast cancer patients when co-infused with peripheral blood progenitor cells [14]. Engraftment of allogeneic MSCs during bone marrow transplantation has led to increased bone mineral deposition and reduced frequency of bone fracture in children who suffer from severe osteogenesis imperfecta $[15,16]$. Moreover, MSCs have also been researched as a vehicle for gene therapy for gut regeneration [17] and hemophilia B [18].

It has been demonstrated by several groups that the origin of MSCs can affect cellular properties and functionalities even if they are cultured under exactly the same conditions. For example, Sakaguchi et al. revealed that human MSCs derived from bone marrow exhibited the strongest osteogenic potential whereas those isolated from synovium were predominant in chondrogenesis and adipogenesis [9]. Similarly, the study carried out by Yoshimura and coworkers showed that evident osteogenesis was detected in periosteum- and muscle-derived rodent MSCs while synovium-derived cells had a stronger potential for chondrogenesis and adipogenesis [6]. This evidence also suggests that the plasticity of MSCs can be species-dependent. Furthermore, MSCs are a very rare population that only accounts for $0.01 \%$ to $0.001 \%$ of the cell numbers in bone marrow [19], and this is even lower in umbilical cord and peripheral blood [20]. Due to their unique characteristics, MSCs are usually purified by plastic adherence and remain highly heterogeneous after isolation. The low frequency and the lack of high homogeneity of freshly extracted MSC populations necessitates extensive in-vitro expansion following isolation prior to various clinical applications and essential manipulation. Thus, the use of MSCs in therapeutic treatments predominantly depends on their ability to replicate in vitro and produce progeny with strong differentiation capacity that can regenerate damaged cells, tissues, or organs. Although MSC populations may be expanded ex vivo for several generations without eliciting expression of a specific differentiated phenotype, senescence can potentially deteriorate MSC fitness to the point where the residual stem cell features are compromised and insufficient to support long-term tissue regeneration [21]. Therefore, it is important to consider the influence of in-vitro aging on cellular characteristics when designing new MSC-based therapeutic strategies.

A number of studies have been conducted to investigate human MSC aging, both in vivo and in vitro. Most of them have focused on the effects of donor age, ranging from 16 months to 90 years old, on MSC performance and have indicated that MSC frequency, population doubling rate, colony forming efficiency, and differentiation capacity decline in samples harvested from older individuals [21-24]. For in-vitro aging, since the actual age of a culture is usually presented by the number of cell population doubling (NCPD), previous research has primarily aimed to identify the upper limit of NCPD where the culture ceases to replicate and loses differentiation capability [21, 22, 25-29]. While a few groups have reported over 40 population doublings from the initial MSC passage to senescence $[25,26]$, others have suggested the maximum of an overall NCPD to be between 15 and 30 [21, 22, 27-29]. These studies also revealed that in-vitro aging can negatively impact the differentiation potential of MSCs, yet this was evaluated mostly on an on/off basis to determine whether or not differentiation toward a specific cell lineage can be achieved [21, $27,28]$ or the percentages of differentiated cells in a population $[22,29]$. The present work sought to not only distinguish the molecular and genetic phenotype of human MSCs at early and late passages within the limit of NCPD allowance (i.e., before cells cease growing or proliferating), but also characterize variations in the quality of their differentiated cells. The effects of expansion or proliferation media on MSC senescence were also investigated.

\section{Methods}

\section{Cultivation of human bone marrow MSCs}

MSCs extracted from the bone marrow of a 21-year-old Hispanic male donor were obtained from ATCC (Manassas, VA, USA). Cells were passaged twice before being distributed to us. To evaluate the phenotypic and morphological changes of in-vitro aging MSCs, cells were seeded on the surface of tissue culture plastics at a constant density of 1500 live cells per $\mathrm{cm}^{2}$ and were 
cultured with either of the two most commonly used MSC proliferation media inside a humidified incubator $\left(37{ }^{\circ} \mathrm{C}, 5 \% \mathrm{CO}_{2}\right)$. The first medium consisted of lowglucose Dulbecco's modified Eagle's medium (DMEM), $10 \%$ fetal bovine serum (FBS), $1 \%$ penicillin/streptomycin, and $1 \mathrm{ng} / \mathrm{mL}$ basic fibroblast growth factor (FGF2) [30-34]. The other medium was composed of minimum essential medium alpha ( $\alpha \mathrm{MEM}), 16.7 \% \mathrm{FBS}$, $1 \%$ penicillin/streptomycin, and 1\% L-glutamine [35-37]. DMEM and $\alpha M E M$ experiments were conducted independently. Culture media were completely renewed at $24 \mathrm{~h}$ post-seeding and every 3 days thereafter. MSCs in monolayer were detached through treatment with $0.15 \%$ trypsin at $37{ }^{\circ} \mathrm{C}$ for $4 \mathrm{~min}$, and collected cells were passaged at the aforementioned initial cell seeding density every 10 days. Phase-contrast images were taken during each expansion process to record cell morphology.

\section{MSC propagation}

To determine the proliferative capability of in-vitro aging MSCs, cells collected at the end of each passage were counted using a trypan blue exclusion method. NCPD [24] and cell population doubling time (CPDT) [23] were then calculated based on the following equations:

$$
\begin{aligned}
& N C P D=3.33 \times \log \left(\frac{N_{t}}{N_{i}}\right) \\
& C P D T=\left(t-t_{i}\right) \times \log \left\{2 \times\left[\log \left(\frac{N_{t}}{N_{i}}\right)\right]^{-1}\right\}
\end{aligned}
$$

where $N_{t}$ and $N_{i}$ are the cell numbers at a specific time point $t$ (day 10) and at initial seeding (day 0), respectively.

\section{Flow cytometry}

MSCs harvested from each passage were assessed for surface marker expression via flow cytometry. Cells were first washed with phosphate-buffered saline (PBS) and incubated with a nonspecific blocking buffer containing $1 \%$ bovine serum albumin for $30 \mathrm{~min}$. After centrifugation and removal of blocking solutions, samples were treated with fluorescently conjugated mouse anti-human antibodies for $45 \mathrm{~min}$. The expression of 10 surface markers was analyzed. Specifically, antibodies against Stro1 (ab190282) and CD73 (ab106677) were purchased from Abcam (Cambridge, MA, USA); CD29 (MCA1949A647), CD34 (MCA547PE), CD44 (MCA89PE), and CD106 (MCA907F) were from Bio-Rad (Kidlington, Oxford, UK); and CD45, CD90, CD105, and CD146 (FM002) were from R\&D Systems (Minneapolis, MN, USA). Amongst the surface antigens detected, CD34 and CD45 are HSC markers and thus are not expected to be expressed by MSCs while the others are MSC-specific markers [11]. Antibodies against mouse IgG were used as the negative staining isotype control. Stained cells were re-suspended in PBS and analyzed in an LSR II Flow Cytometer (BD Biosciences, San Jose, CA, USA). The size and granularity of MSCs at each passage were also evaluated using the forward and side scatter diagram in flow cytometry.

\section{MSC adipogenic and osteogenic differentiation}

To determine the differentiation potential, MSCs at selected passages were first incubated with either DMEMbased or aMEM-based proliferation medium for 10 days as previously described and were immediately subjected to adipogenic or osteogenic conditions at the end of the expansion process without detaching the cells from the surface. The adipogenic medium was composed of highglucose DMEM, 10\% FBS, 1\% penicillin/streptomycin/ fungizone, $3.72 \mathrm{mg} / \mathrm{mL}$ sodium bicarbonate, $10 \mu \mathrm{L} / \mathrm{mL}$ insulin, $1 \mu \mathrm{M}$ dexamethasone, $0.5 \mathrm{mM}$ indomethacin, and $60 \mu \mathrm{M}$ 3-isobutyl-1-methylxanine. In the osteogenic experiments, MSCs were fed with high-glucose DMEM supplemented with 10\% FBS, 1\% penicillin/streptomycin/ fungizone, $3.72 \mathrm{mg} / \mathrm{mL}$ sodium bicarbonate, $50 \mu \mathrm{g} / \mathrm{mL}$ ascorbic acid, and $10 \mathrm{mM} \beta$-glycerophosphate. Cells were cultivated with either differentiation medium for up to 21 days with medium exchange every 3 days and were harvested at designated time points for assessment of gene expression and extracellular matrix (ECM) synthesis.

\section{Quantitative real-time polymerase chain reaction}

Gene expression profiles of passaged MSCs and differentiated cells were quantified by real-time polymerase chain reaction (qPCR). Briefly, harvested cells were fixed in TRIzol, and RNA was extracted from the homogenized cell lysate through a series of rinse, elution, and centrifugation steps. The RNA samples were then reverse transcribed into cDNA using SuperScript III reagents (Life Technologies, Grand Island, NY, USA) following the manufacturer's instructions. In the differentiation studies, the gene expression of interest was determined using Taqman qPCR probes (Life Technologies). Two adipogenic (lipoprotein lipase (LPL) and peroxisome proliferator-activated receptor $\gamma($ PPAR $\gamma))$ and three osteogenic (type I collagen (Col I), runt-related transcription factor 2 (RUNX2), and alkaline phosphatase (ALP)) markers were examined. cDNA derived from MSCs at passages 4 (P4) and 8 (P8) was analyzed by a customized qPCR array (Qiagen, Hilden, Germany) that implements the SYBR Green real-time telomeric repeat amplification protocol. Eight stemness genes and fifty potential MSC markers were screened (Table 1). The fluorescent signals were amplified and detected using a StepOnePlus sequence detector (Life Technologies). The reaction consisted of an initial enzyme activation for $10 \mathrm{~min}$ at $95{ }^{\circ} \mathrm{C}$, followed by 40 cycles of $15 \mathrm{~s}$ at $95{ }^{\circ} \mathrm{C}$ 
Table 1 Stem cell genes analyzed in real-time polymerase chain reaction array

\begin{tabular}{ll}
\hline & Gene name \\
\hline Stemness genes & FGF2, INS, LIF, POU5F1, SOX2, TERT, WNT3A, ZFP42 \\
Mesenchymal stem & ALCAM, ANPEP, ANXA5, BDNF, BGLAP, BMP2, BMP7, CASP3, CD44, COL1A1, CSF2, CSF3, CTNNB1, EGF, ENG, ERBB2, FUT1, \\
cell genes & FUT4, FZD9, GTF3A, HGF, ICAM1, IFNG, IGF1, IL10, IL1B, IL6, ITGA6, ITGAV, ITGB1, KDR, KITLG, MCAM, MMP2, NES, NGFR, \\
& NT5E, NUDT6, PDGFRB, PIGS, PROM1, PTPRC, SLC17A5, TGFB3, THY1, TNF, VCAM1, VEGFA, VIM, VWF \\
\hline
\end{tabular}

and $1 \mathrm{~min}$ at $60^{\circ} \mathrm{C}$. The cycle threshold $(\mathrm{Ct})$ value for each sample was averaged from triplicates. A $2^{-\Delta \Delta \mathrm{Ct}}$ approach [38] was used where the fluorescent signals were normalized to the corresponding housekeeping gene (glyceraldehyde-3-phosphate dehydrogenase (GAPDH)). For easy comparison, a heatmap was created for each expansion condition (i.e., DMEM-based and $\alpha M E M-$ based groups) based on the qPCR array data.

\section{Histology}

Samples collected in the differentiation experiments were fixed in $10 \%$ formalin for $1 \mathrm{~h}$ at room temperature and were processed for histological evaluation. Adipogenic samples were first treated with $60 \%$ isopropanol for $5 \mathrm{~min}$, followed by 5 -min incubation with $1.8 \% \mathrm{w} / \mathrm{v}$ Oil Red $\mathrm{O}$ dissolved in isopropanol to stain lipids. Osteogenic specimens were incubated with $2 \% \mathrm{w} / \mathrm{v}$ Alizarin Red S dissolved in deionized water for $45 \mathrm{~min}$ to visualize calcium. Several rinses with water were made between each step. Color images were captured under a light microscope (Nikon Eclipse Ti, Tokyo, Japan).

\section{Statistical analyses}

Statistical data are presented as means \pm one standard deviation. Statistical analyses were performed by Student's $t$ test for comparison between two groups or by one-way analysis of variance in conjunction with a Bonferroni post-test for multiple comparisons with significance set at a $p$ value of less than 0.05 .

\section{Results}

Reduced proliferative capability of in-vitro aging MSCs

MSCs were processed for subculture every 10 days, and NCPD and CPDT were measured at the end of each passage (Fig. 1). Although MSCs nourished with the DMEM-based expansion medium exhibited stronger proliferative capability in the initial passages compared to the other group, the average NCPD started to fall behind after P6 (Fig. 1a). Specifically, NCPD in the DMEM cultures dropped significantly from 4.04 in P3 to 1.27 in P8. While MSCs exposed to the $\alpha M E M-b a s e d$ culture condition were able to maintain a similar cell doubling rate up to P5 with an average NCPD of $\sim 3.1$, the value gradually declined thereafter and reached 1.84 in P8. Overall, NCPD decreased by $69 \%$ and $41 \%$ from P3 to P8 and accumulative NCPD was around 16.9 and 16.2 at the end of P8 in the DMEM and $\alpha$ MEM groups,

\section{a Cell Doubling Number}

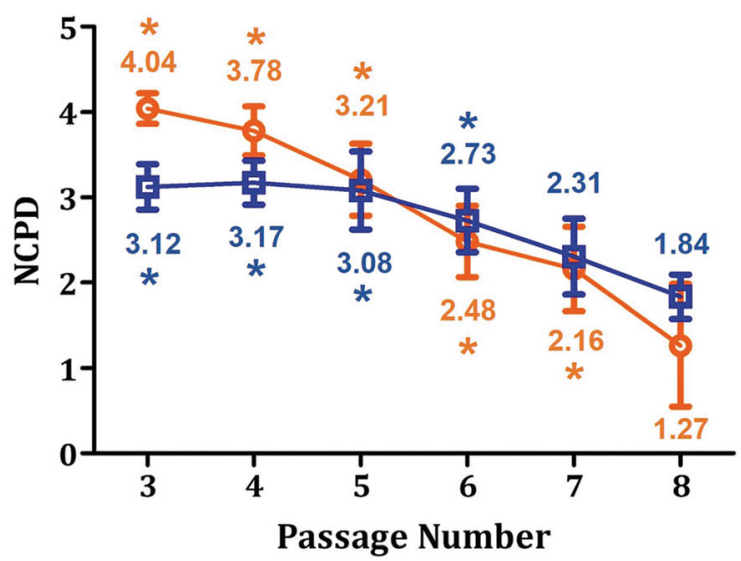

- DMEM $\because \alpha$ MEM

b Cell Doubling Time

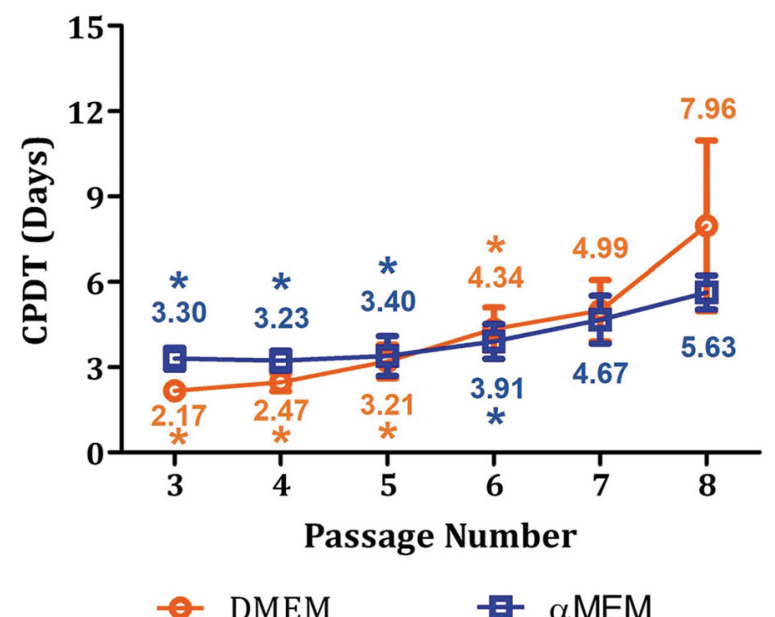

Fig. 1 Propagation of in-vitro aging MSCs. a Numbers of cell population doubling (NCPD) decreased by $69 \%$ and $41 \%$ from P3 to P8 in the DMEM and aMEM groups, respectively. $\mathbf{b}$ As a result of the reduced proliferative capability, MSC population doubling time (CPDT) increased over time in both groups. Numbers represent the mean values. $n=5-8$; ${ }^{*} p<0.05$, versus the corresponding P8-MSCs cultured under the same expansion condition. aMEM, minimum essential medium alpha; DMEM, Dulbecco's modified Eagle's medium 
respectively. Conversely, CPDT extended from 2.17 to 7 . 96 days in the DMEM group and from 3.3 to 5.63 days in the $\alpha M E M$ group as the passage number increased from 3 to 8 (Fig. 1b).

\section{Increased morphological inhomogeneity of in-vitro aging MSCs}

Microscopic images demonstrate that while most of the MSCs cultured with either medium formulation maintained their normal spindle shape in the early passages up to P5, those at later passages exhibited less concordant cell morphologies with some of them possessing irregular flattened geometry and enlarged size (Fig. 2). Morphological distribution of in-vitro aging MSCs was determined by the size-granularity diagram in flow cytometry where cells were divided into three subpopulations (S1, S2, and S3) as shown in Fig. 3a. In the early passages, MSC populations were more concentrated and primarily occupied the subpopulation $S 1$ region. As the passage number increased, the main MSC population started shifting from $S 1$ to $S 2$ and $S 3$ in both groups. Specifically, in the DMEM group (Fig. 3b), $S 1$ downsized by $64 \%$ from P3 $(86.7 \%)$ to P8 $(31.4 \%)$ whereas $S 2$ and
S3 populations rose from $13.4 \%$ and $1.6 \%$ in P3 to $54.1 \%$ and $15.0 \%$ in P8, respectively. Similarly, the size of $S 1$ in the $\alpha$ MEM group decreased over time from $85.5 \%$ (P3) to $65.1 \%$ (P8) while both $S 2$ and $S 3$ expanded as MSCs aged in vitro (Fig. 3c). Morphologically, more inhomogeneous MSC populations were detected in the cultures with a passage number of 6 or higher in both DMEM and $\alpha$ MEM groups.

\section{Variations in CD106 and CD146 levels}

Surface antigen expression of passaged MSCs was assessed by flow cytometry (Fig. 4). Eight MSC-specific markers, Stro-1, CD29, CD44, CD73, CD90, CD105, CD106, and CD146, and two HSC markers, CD34 and $\mathrm{CD} 45$, were evaluated. While most of the MSC-positive markers including CD29, CD44, CD73, CD90, and CD105 were highly expressed by at least $96.6 \%$ of the cells across different passages in both DMEM (Fig. 4a) and $\alpha M E M$ (Fig. 4b) groups, expression of CD106, CD146, and Stro-1 was somehow variable. Specifically, CD106 levels oscillated throughout the entire expansion process with the average values ranging from $34.6 \%$ (P7) to $55.4 \%$ (P3) in the DMEM group and from $20.2 \%$ (P6)

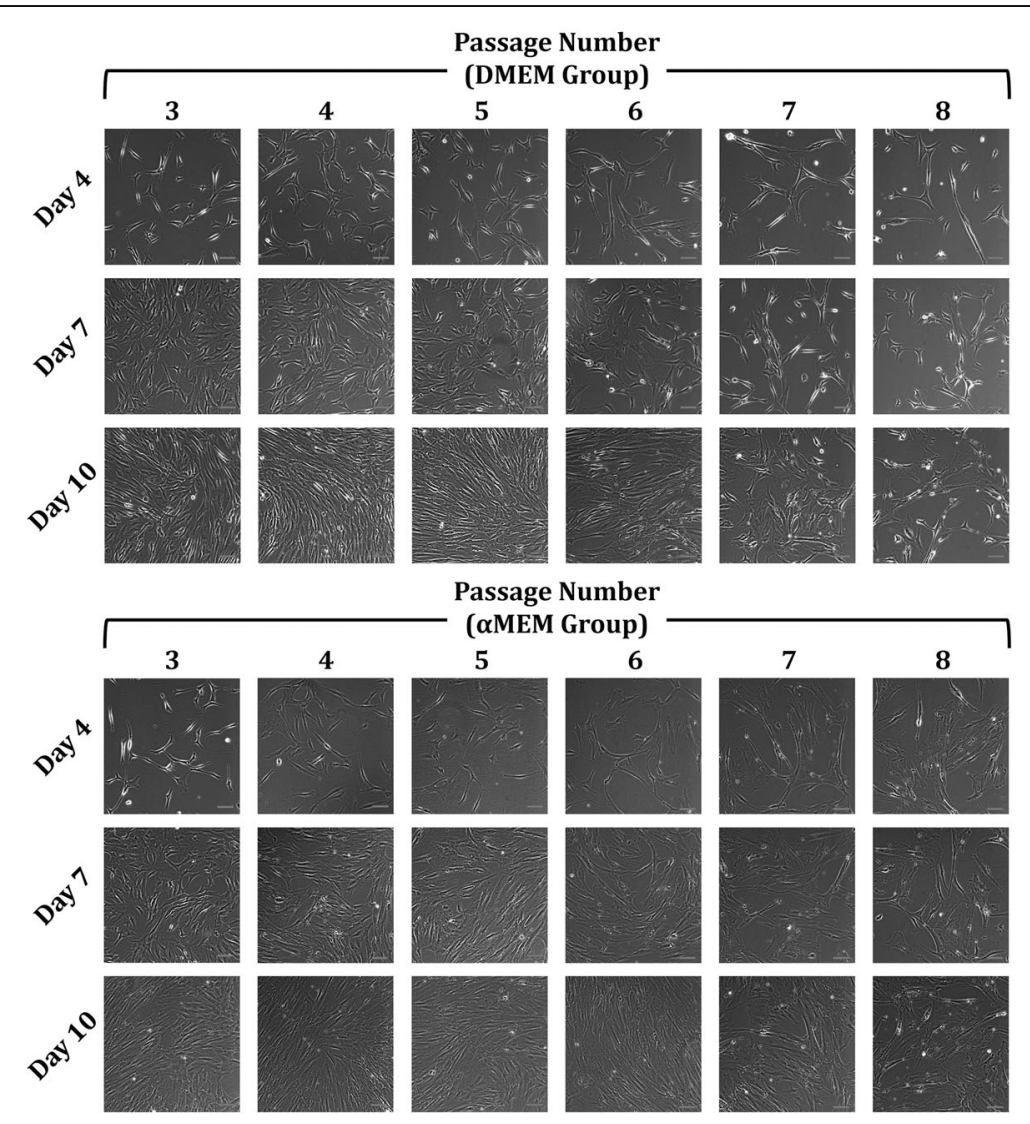

Fig. 2 Morphological representation of in-vitro aging MSCs. Phase-contrast images of MSCs at P3 through P8 exposed to the DMEM-based (top panel) and aMEM-based (bottom panel) culture conditions were captured on days 4, 7, and 10. Scale bars $=100 \mu \mathrm{m}$. aMEM, minimum essential medium alpha; DMEM, Dulbecco's modified Eagle's medium 


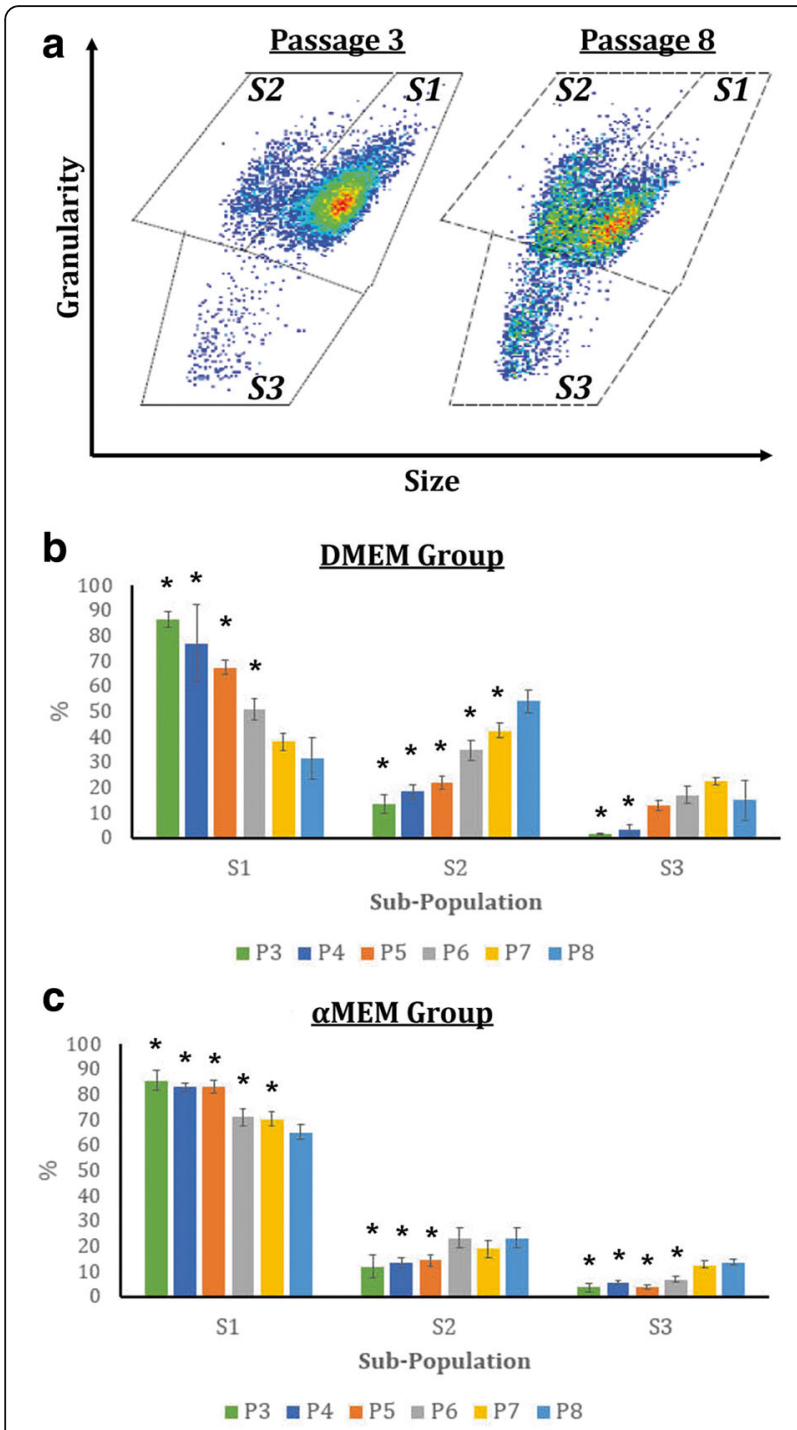

Fig. 3 Morphological evaluation of in-vitro aging MSCs. a Passaged MSCs were divided into three subpopulations, S1, S2, and S3, based on the forward (size) and side (granularity) scatter parameters in flow cytometry analysis. b, c Cell counts in the main subpopulation, S1, decreased by $64 \%$ and $24 \%$ from P3 to P8 in the DMEM (b) and aMEM (c) groups, respectively. $n=20 ;{ }^{*} p<0.05$, versus the corresponding P8-MSCs within the same subpopulation. aMEM, minimum essential medium alpha; DMEM, Dulbecco's modified Eagle's medium

to $62.7 \%$ (P3) in the $\alpha M E M$ group. The size of CD146 ${ }^{+}$ populations stayed similar at all point in the $\alpha M E M$ group (76.5-97.3\%) but continued to shrink in the DMEM group as the passage number increased $(95.1 \%$ in P3 versus $49.7 \%$ in P8). Despite being an MSCpositive marker, Stro-1 levels were extremely low compared with the other positive markers in any passages in both groups, and only about 9\% of passaged MSCs contained Stro-1. Moreover, the majority of MSCs passaged under either condition remained negative for both CD34 and CD45.
Gene expression profiles of in-vitro aging MSCs affected by medium composition

A qPCR array was used to determine gene expression profiles of passaged MSCs (Fig. 5). The outcome is quite distinct when cells were cultured with different proliferation media. In the DMEM group, four stemness (FGF2, INS, LIF, and SOX2) and eight MSC-specific (BDNF, CASP3, COL1A1, FUT1, FZD9, ICAM1, IL6, and VCAM1) genes decreased by more than $50 \%$ in $\mathrm{P} 8$ versus $\mathrm{P} 4$, and another 11 markers reduced by $30-50 \%$ (Fig. 5a). When MSCs were exposed to the aMEMbased culture condition, three stemness (INS, LIF, and ZFP42) and 20 MSC-specific (BMP2, BMP7, CSF2, CSF3, FUT1, HGF, ICAM1, IFNG, IGF1, IL1B, IL6, KITLG, NES, NGFR, PROM1, PTPRC, TGFB3, TNF, VWF, and VCAM1) genes were downregulated by more than $50 \%$ in P8 versus P4, and another eight markers lowered by $30-50 \%$ (Fig. 5b). Interestingly, amongst the genes examined, only one of them (WNT3A) in the aMEM group, but 10 (ANPEP, BGLAP, BMP2, CTNNB1, HGF, IL10, ITGA6, KDR, SLC17A5, and VWF) in the DMEM group were upregulated by more than 50\% in P8-MSCs in comparison with P4-MSCs.

\section{Better preservation of adipogenic over osteogenic potential by in-vitro aging MSCs}

Adipogenic and osteogenic differentiation capacities of passaged MSCs were investigated and the results derived from P4 (early passage) and P8 (late passage) cells were reported. When the populations were expanded under the DMEM-based condition, both P4-MSCs and P8MSCs could differentiate into adipocytes after 21 days of induction as evidenced by elevated expression of LPL and PPAR $\gamma$ genes and synthesis of lipid vacuoles (Fig. 6). Specifically, in comparison with nonconditioned MSCs at the corresponding passages, levels of LPL and PPAR increased by 5865 -fold and 16.1-fold, respectively, in the differentiated P4 cells (Fig. 6a) and by 356-fold and 6.7fold, respectively, in the differentiated P8 cells (Fig. 6b). The cells undergoing adipogenesis not only changed their morphologies to a polygonal or round shape, but also produced abundant lipids (Fig. 6c, d). On the contrary, P4-MSCs treated with osteogenic differentiation media for 9 days exhibited significantly stronger expression of Col I (1.98-fold), RUNX2 (1.88-fold), and ALP (6.14-fold) genes than those in the undifferentiated state (Fig. 6a) while only the RUNX2 signal (2.37-fold) was amplified in the P8 group (Fig. 6b). Moreover, cells with a similar appearance uniformly distributed in the P4 osteogenic cultures (Fig. 6c) as opposed to those at P8 which had relatively discordant cell shapes.

A similar outcome was demonstrated in the $\alpha M E M$ group (Fig. 7). In gene expression, LPL and PPAR $\gamma$ signals were amplified in both P4 (21,868-fold in LPL, 

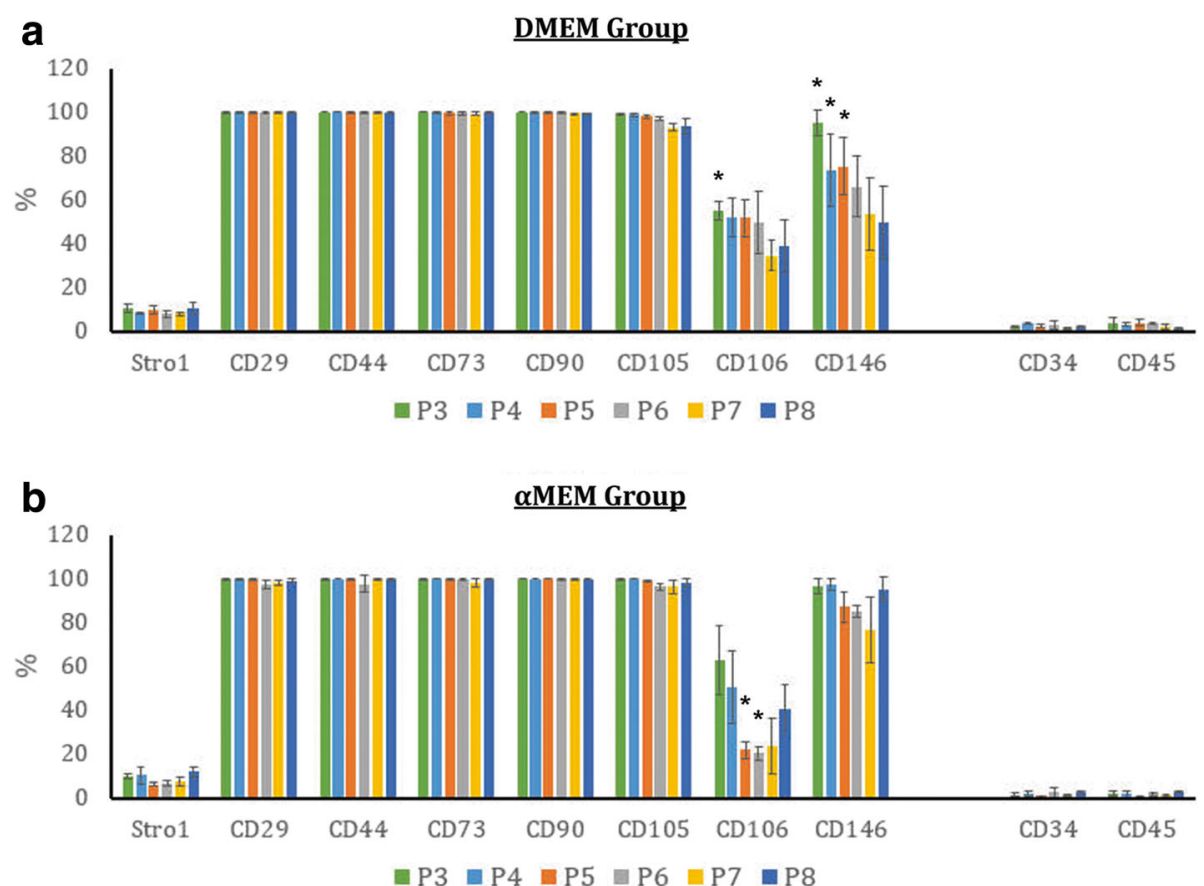

Fig. 4 Surface marker expression of in-vitro aging MSCs. MSCs were cultivated with either DMEM-based (a) or aMEM-based (b) expansion media and were analyzed by flow cytometry for the expression of specific MSC positive (Stro-1, CD29, CD44, CD73, CD90, CD105, CD106, CD 146) and negative (CD34, CD45) surface antigens. $n=4-6 ;{ }^{*} p<0.05$, versus the corresponding P8-MSCs cultured under the same expansion condition within the same surface marker analysis. aMEM, minimum essential medium alpha; DMEM, Dulbecco's modified Eagle's medium

2666-fold in PPARY; Fig. 7a) and P8 (6550-fold in LPL, 2345 fold in PPAR $;$; Fig. 7b) adipogenic cultures. Levels of Col I, RUNX2, and ALP were, respectively, 1.58-fold, 2.73-fold, and 6.53-fold higher in osteogenically differentiated cells than nonconditioned P4-MSCs (Fig. 7a) whereas incubation with osteogenic differentiation media only stimulated RUNX2 expression (6.47-fold) in the P8 samples (Fig. 7b). Phase-contrast images demonstrate morphological changes of P4-MSCs (Fig. 7c) and P8-MSCs (Fig. 7d) during adipogenic and osteogenic induction.

\section{Compromised properties of cells differentiated from aged MSCs}

Gene expression and ECM synthesis of cells differentiated from P4-MSCs and P8-MSCs were directly compared. In the DMEM group, levels of Col I and ALP in the P4 cells were respectively 3.72-fold and 14.3-fold higher than those in the P8 cells after 9-day osteogenic induction while RUNX2 expression was comparable (Fig. 8a). Additionally, calcium deposition was barely detectable in the P8 samples whereas the intensity of calcium staining increased over time in the P4 cultures (Fig. 8c). During adipogenesis, P4-MSCs differentiated into cells that had 8.77-fold stronger LPL gene expression (Fig. 8b) and synthesized more lipid vacuoles (Fig. 8d) after 21 days in culture as opposed to the $\mathrm{P} 8$ group.

Osteogenic differentiation of P4-MSCs that were initially expanded in the $\alpha M E M-b a s e d$ medium led to elevated expression of Col I (4.43-fold) and ALP (52.8-fold) genes and an equal RUNX2 level compared with P8MSCs (Fig. 9a). Similarly, LPL and PPARY signals of the P4 adipogenic samples were respectively 5.71-fold and 4 . 18-fold stronger than the P8 specimens (Fig. 9b). Although some calcium staining was detected on day 9 in the P8 osteogenic group, osteoblast-like cells derived from P4-MSCs deposited relatively more calcium (Fig. 9c). When exposed to adipogenic conditions, both P4-MSCs and P8-MSCs were able to produce lipids, though more lipid vacuoles were observed in the P4 group (Fig. 9d). Histological evaluation also demonstrated that most of synthesized lipids accumulated in the cytoplasm (Figs. 8d and 9d).

\section{Discussion}

Cell aging is a complex process and current thoughts on mechanisms underlying senescence have mainly focused on the loss of telomere length. In a preliminary study, the relative telomere length of MSCs at different passage numbers was measured using the Cawthon's qPCR method [39] and a decreasing trend was observed over 


\begin{tabular}{|c|c|c|c|}
\hline \multicolumn{2}{|c|}{ DMEM Group } & \multicolumn{2}{|c|}{$\underline{\alpha M E M ~ G r o u p}$} \\
\hline ALCAM & ITGA6 & ALCAM & ITGA6 \\
\hline ANPEP & ITGAV & ANPEP & ITGAV \\
\hline ANXA5 & ITGB1 & ANXA5 & ITGB1 \\
\hline BDNF & $K D R$ & $B D N F$ & $K D R$ \\
\hline BGLAP & KITLG & BGLAP & KITLG \\
\hline BMP2 & LIF & BMP2 & LIF \\
\hline BMP7 & MCAM & BMP7 & MCAM \\
\hline CASP3 & MMP2 & CASP3 & MMP2 \\
\hline$C D 44$ & NES & $C D 44$ & NES \\
\hline COL1A1 & NGFR & COL1A1 & NGFR \\
\hline CSF2 & NT5E & CSF2 & NT5E \\
\hline CSF3 & NUDT6 & CSF3 & NUDT6 \\
\hline CTNNB1 & PDGFRB & CTNNB1 & PDGFRB \\
\hline$E G F$ & PIGS & $E G F$ & PIGS \\
\hline$E N G$ & POU5F1 & $E N G$ & POUSF1 \\
\hline ERBB2 & PROM1 & ERBB2 & PROM1 \\
\hline$F G F 2$ & PTPRC & $F G F 2$ & PTPRC \\
\hline FUT1 & SLC17A5 & FUT1 & SLC17AS \\
\hline FUT4 & sox2 & FUT4 & sox2 \\
\hline$F Z D 9$ & TERT & $F Z D 9$ & TERT \\
\hline GTF3A & TGFB3 & GTF3A & TGFB 3 \\
\hline HGF & THY1 & HGF & THY1 \\
\hline ICAM1 & $T N F$ & ICAM1 & $T N F$ \\
\hline IFNG & VCAM1 & IFNG & VCAM1 \\
\hline IGF1 & VEGFA & IGF1 & VEGFA \\
\hline IL10 & VIM & IL10 & VIM \\
\hline$I L 1 B$ & $V W F$ & $I L 1 B$ & $V W F$ \\
\hline IL6 & WNT3A & IL6 & WNT3A \\
\hline INS & ZFP42 & INS & ZFP42 \\
\hline & zulation & up-re & \\
\hline$>100$ & & & $100 \%$ \\
\hline
\end{tabular}

Fig. 5 Gene expression profiles of P8-MSCs in comparison with P4-MSCs. MSCs were cultivated with either DMEM-based (a) or aMEM-based (b) expansion media and were analyzed by GPCR array for the expression of eight stemness (FGF2, INS, LIF, POU5F1, SOX2, TERT, WNT3A, ZFP42) and fifty MSC-specific genes. GAPDH was used as the reference gene, and the corresponding P4-MSCs were used as the control groups. aMEM, minimum essential medium alpha; DMEM, Dulbecco's modified Eagle's medium

time in both DMEM (Additional file 1: Figure S1C) and aMEM (Additional file 1: Figure S1D) groups. Although different telomere lengths of MSCs have been reported in the literature, ranging from $7 \mathrm{~kb}$ to $13 \mathrm{~kb}$ depending on donor age, all these studies concluded telomere loss of up to $2 \mathrm{~kb}$ when MSCs are passaged in vitro [21, 29, 40]. Furthermore, some groups have also demonstrated that MSCs harvested from telomerase knock-out animals have compromised replicative capacity [41] and can completely lose the ability to differentiate, even in early passages [42]. On the contrary, MSCs transduced with telomerase reverse transcriptase exhibited prolonged proliferative lifespan and enhanced osteogenic potential [43, 44]. However, the efficiency of this genetic engineering approach to the generation of large MSC populations for clinical purposes is still unclear. Another possible contributing factor to cell senescence is the $\mathrm{p} 16^{\mathrm{INK} 4 \mathrm{~A}}$ gene, the expression of which has been shown to be closely associated with MSC aging and to be silenced by DNA methylation during in-vitro expansion, leading to chromosomal aberrations [45]. Recently, Blázquez-Prunera et al. formulated a culture medium with a xeno-free supplement derived from human plasma that held promise for the maintenance of MSC phenotype, multipotency, and genetic stability during in-vitro passage [46]; however, more studies on this defined xeno-free human plasma fraction are necessary to confirm its effectiveness.

In the present study, we designed a series of experiments to explore changes in cell morphology, proliferative rate, surface marker and gene expression, and differentiation capability of human MSCs undergoing invitro aging and included two recipes for MSC proliferation media that are the most commonly used in the field. Given that the initial MSC batch we received were P2 cells and could achieve an additional 21.15 doublings as recommended by the vendor (documents not shown; ATCC lot no. 62535836), we evaluated MSCs with an accumulative NCPD of up to 16.9 in the DMEM group and 16.2 in the $\alpha M E M$ group. We estimated that the overall NCPD of the cells examined in this study should stay under 25 which falls in the effective range (15-30) reported by several other groups [21, 22, 27-29], assuming the individual NCPD in the first two passages, i.e., P1 and P2, did not deviate too much from our P3 data shown in Fig. 1a. Our results indicate that the DMEMbased expansion condition better facilitated MSC proliferation in the early passages (P3 and P4), but NCPD in this group rapidly dropped thereafter. A relatively steady NCPD curve was observed in the $\alpha$ MEM-supplemented culture. Overall, passaged MSCs exhibited a tendency to lose the ability of mitotic divisions during in-vitro aging as evidenced by the decrease in NCPD by $69 \%$ and $41 \%$ from P3 to P8 in the DMEM and $\alpha$ MEM groups, respectively (Fig. 1a), which is in agreement with previous investigations [21, 22, 25, 27-29]. As a result of compromised replicative capacity, CPDT rose over time in both groups when the passage number increased (Fig. 1b). Morphologically, instead of a uniform fibroblast-like spindle shape observed in the early cultures, some of MSC populations displayed enlarged and flattened appearance in the later passages (Fig. 2). It is believed that an increase in cell size is highly associated with senescence in vitro $[12,47]$. Our flow cytometry analysis further confirms that in-vitro aging can contribute to a more scattered distribution of MSC populations in the late passages, which substantiates morphological abnormality and inhomogeneity (Fig. 3). We also found that the $\alpha M E M-b a s e d$ proliferation medium may preserve MSC morphology for a relatively longer period as opposed to the DMEM group (Fig. 3b and c). 

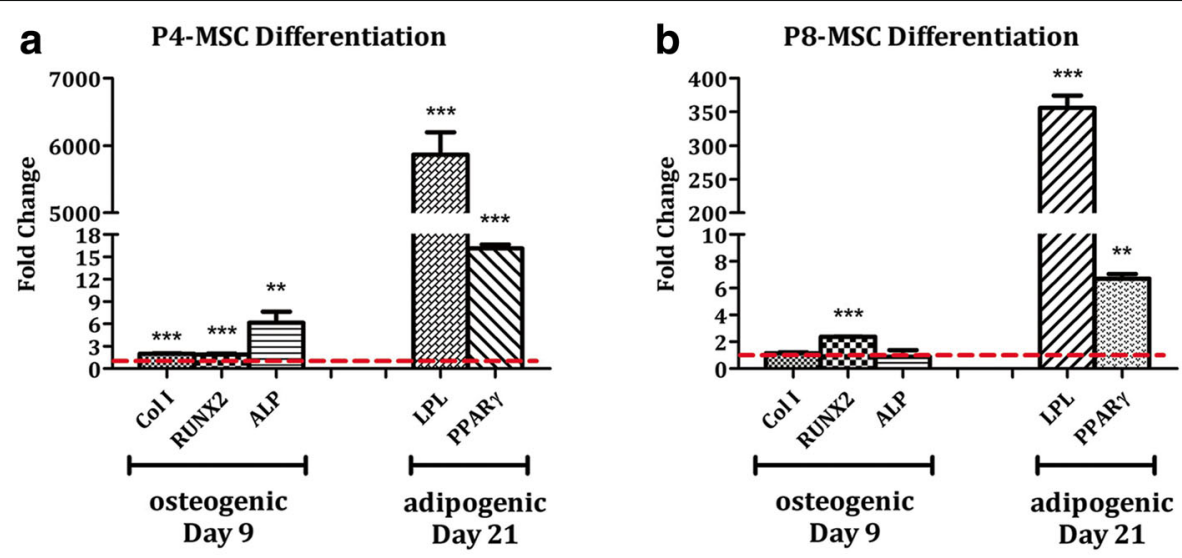

C

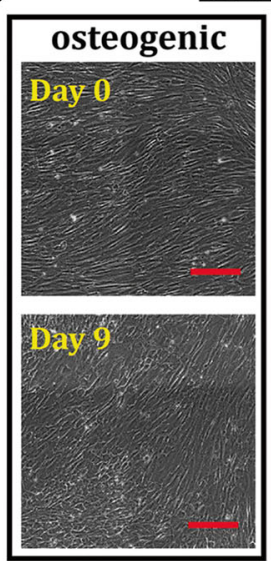

P4-MSCs

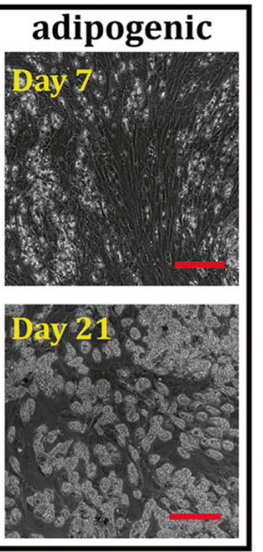

d

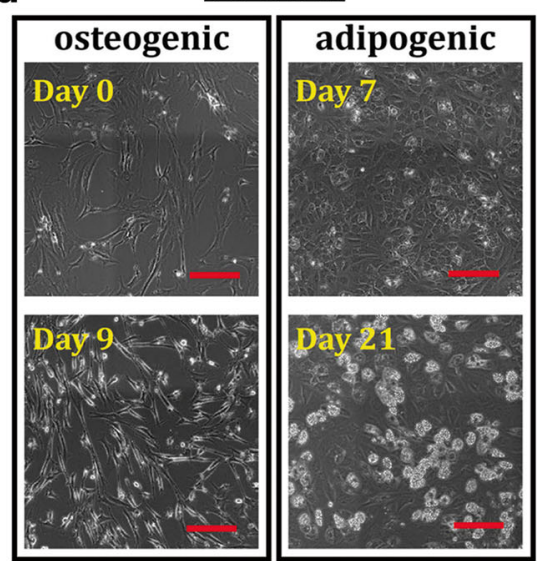

Fig. 6 Adipogenic and osteogenic differentiation of MSCs derived from the DMEM-based expansion condition. MSCs at P4 (a, c) or P8 (b, d) were cultivated with either osteogenic differentiation media for 9 days or adipogenic differentiation media for 21 days. $\mathbf{a}$, $\mathbf{b}$ Expression of osteogenic (Col I, RUNX2, ALP) and adipogenic (LPL, PPARY) genes was determined by qPCR with GAPDH as the reference gene and nonconditioned MSCs at the corresponding passages as the control groups (red dashed lines). $n=4$; $^{* *} p<0.01$, ${ }^{* * *} p<0.001$, versus nonconditioned P4-MSCs or P8-MSCs. c, d Phase-contrast images of osteogenic and adipogenic samples were captured at the designated time points. White clusters in the adipogenic images represent lipids produced by the cells. Scale bars $=250 \mu \mathrm{m}$. ALP, alkaline phosphatase; Col I, type I collagen; LPL lipoprotein lipase; MSC, mesenchymal stem cell; P, passage; PPAR , peroxisome proliferator-activated receptor $\gamma$; RUNX2, runt-related transcription factor 2

The expression of eight MSC and two HSC surface markers was assessed (Fig. 4). As expected, passaged MSCs remained negative for both CD34 and CD45 throughout the entire expansion process. At least 96.6\% of the MSC populations expressed CD29, CD44, CD73, CD90, and CD105 antigens regardless of culture condition and passage number. Stro- 1 levels were found to be lower than $10 \%$ in any passages when MSCs were cultivated with either DMEM-based or $\alpha$ MEM-based proliferation medium. It is thought that Stro-1 is unlikely to be a common MSC marker and may only be used for initial MSC isolation because its expression is not exclusive to MSCs and can quickly disappear during in-vitro expansion [11, 48]. In addition, passaged MSCs displayed variable CD106 levels in both groups that were not proportionate to passage number. It has been previously revealed that $\mathrm{CD} 106^{+}$and $\mathrm{CD} 106^{-}$cells coexist in
MSC populations and both populations possess multipotent capacity, although $\mathrm{CD} 106^{+} \mathrm{MSCs}$ have more immunoregulatory effects on $\mathrm{T}$ helper subsets [49] and stronger potential for capillary tubular formation than $\mathrm{CD} 106^{-}$cells [50]. Therefore, oscillated CD106 expression may not be attributed to in-vitro MSC aging. A decreasing trend in the CD146 signal was detected only in the DMEM-supplemented samples (Fig. 4a). As demonstrated by Sacchetti et al., osteoprogenitor cells that regenerate bone and organize hematopoietic microenvironments are highly positive for CD146 [51], and thus the reduction in CD146 may subsequently impair the osteogenic potential of aged MSCs in the DMEM group when compared with the $\alpha M E M$ group. We further analyzed the surface marker expression in each of the three MSC subpopulations, $S 1, S 2$, and $S 3$, as defined in Fig. 3a; however, there was no obvious correlation 

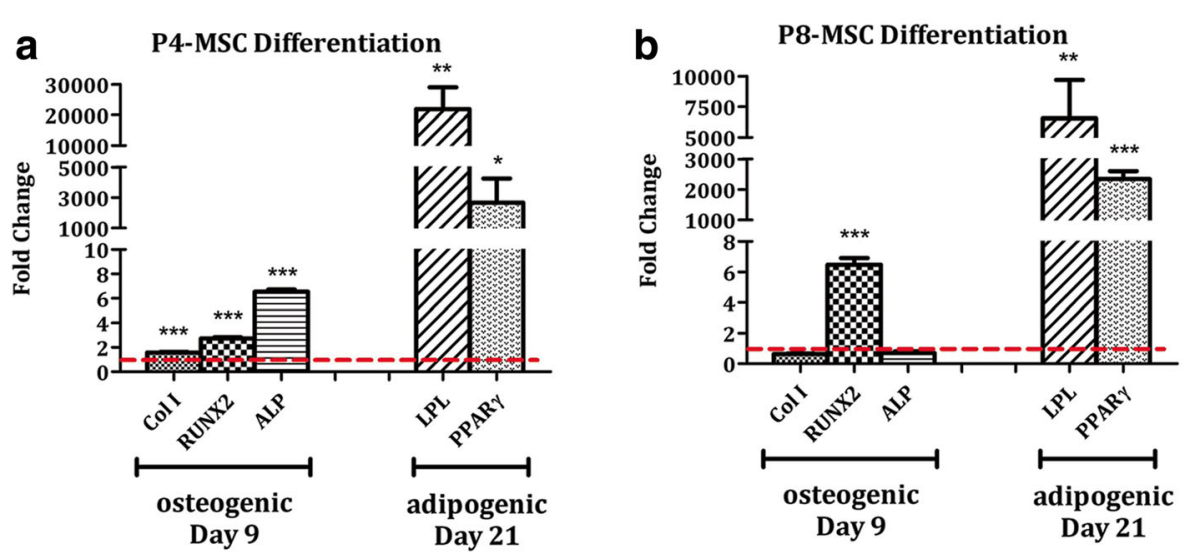

C

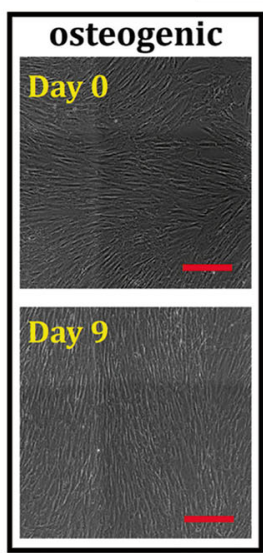

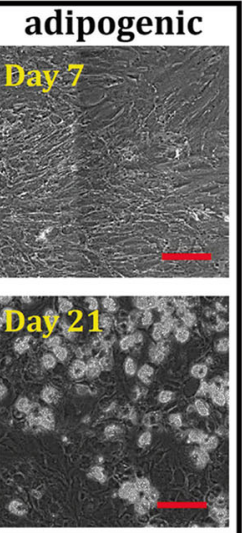

d

P8-MSCs

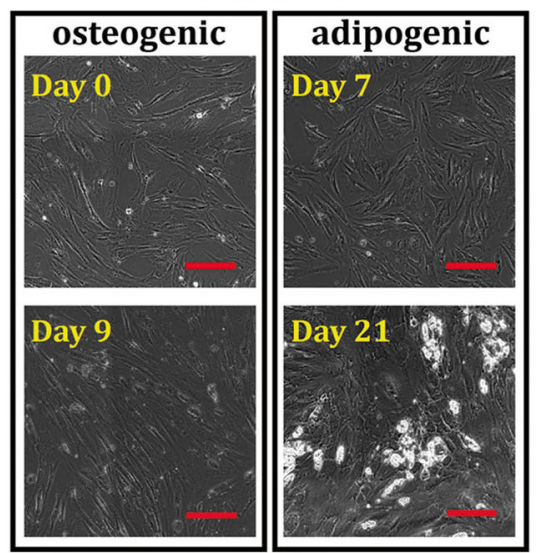

Fig. 7 Adipogenic and osteogenic differentiation of MSCs derived from the aMEM-based expansion condition. MSCs at P4 (a, c) or P8 (b, d) were cultivated with either osteogenic differentiation media for 9 days or adipogenic differentiation media for 21 days. $\mathbf{a}, \mathbf{b}$ Expression of osteogenic (Col I, RUNX2, ALP) and adipogenic (LPL, PPARY) genes was determined by GPCR with GAPDH as the reference gene and nonconditioned MSCS at the corresponding passages as the control groups (red dashed lines). $n=4 ;{ }^{*} p<0.05,{ }^{* *} p<0.01,{ }^{* * *} p<0.001$, versus non-conditioned P4-MSCS or P8-MSCs. c, d Phase-contrast images of osteogenic and adipogenic samples were captured at the designated time points. White clusters in the adipogenic images represent lipids produced by the cells. Scale bars $=250 \mu \mathrm{m}$. ALP, alkaline phosphatase; Col I, type I collagen; LPL lipoprotein lipase; MSC, mesenchymal stem cell; P, passage; PPARY, peroxisome proliferator-activated receptor $\gamma$; RUNX2, runt-related transcription factor 2

between the two parameters (data not shown), implying that surface marker expression may not be affected by morphological changes of in-vitro aging MSCs.

Expression of over 30 stem cell genes evaluated in this study differed in MSCs derived from early (P4) and late (P8) passages (Fig. 5). While qPCR signals from about one-third of the altered genes in the DMEM group increased in P8 versus P4, only one gene was upregulated in the $\alpha M E M$ group. This outcome suggests that: 1) invitro senescence can lead to genetic instability of MSCs; and 2) gene expression of aging MSCs is highly regulated by culture media that are selected to expand the populations and thereby should be considered carefully. It is noteworthy that the genetic instability of aging MSCs may subsequently result in altered levels of ECM components and growth factors secreted by the cells; this requires further investigation.
Our results also show that while MSCs at early passages (P4) derived from either expansion condition were able to develop into adipocyte-like and osteoblast-like cells upon proper stimulation, lineage-dependent differentiation capacity was detected in cells at later passages (P8) (Figs. 6, 7, 8 and 9). Adipogenic differentiation was achieved in both P4 and P8 cultures as evidenced by elevated expression of adipocyte-associated genes (LPL and PPAR $\gamma$ ) and production of abundant lipid vacuoles in comparison with unstimulated MSCs (Figs. 6 and 7). Although expression of LPL and/or PPAR genes was somehow compromised in the P8 samples compared to the corresponding $\mathrm{P} 4$ groups, it did not affect the ability of cells differentiated from P8-MSCs to synthesize lipids (Figs. 8 and 9). During osteogenesis, however, cells derived from P8-MSCs had relatively discordant morphologies and only RUNX2 levels were higher than the 


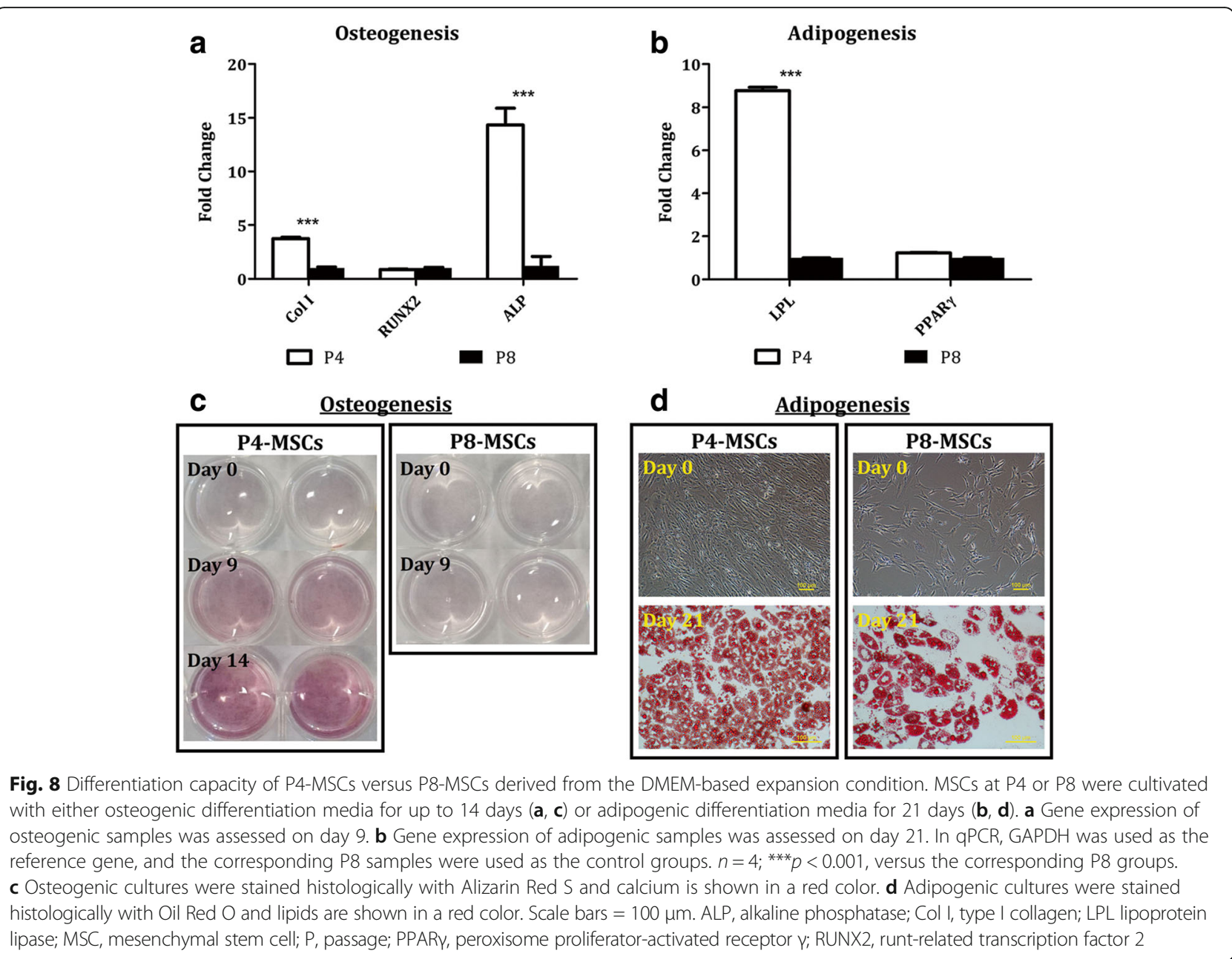

controls after 9 days in culture (Figs. 6 and 7). Calcium deposition as well as qPCR signals from both Col I and ALP genes reduced in P8 versus P4, while RUNX2 expression was comparable (Figs. 8 and 9). Since RUNX2 is a key transcription factor involved in the early phase of osteogenesis [52, 53], it may require more time for the P8 samples to complete the differentiation process. However, spontaneous cell detachment was observed during osteogenesis in the P8 cultures in both DMEM and $\alpha M E M$ groups such that the differentiation induction only lasted up to 10 days. Even in the early passages, cell detachment also occurred in the DMEM group and the P4 osteogenic experiments could only run for 2 weeks. The reasons behind this spontaneous cell detachment remain unknown and further investigations are necessary. Histologically, although the intensity of calcium staining was extremely weak in the P8 osteogenic cultures, some accumulation was detected in the aMEM group (Fig. 9c) whereas no stains were viewed in the DMEM group (Fig. 8c). In summary, despite some contradictory results that indicated quick dissipation of adipogenic capacity of aged MSCs [27-29], our findings suggest that adipogenic potential may be better preserved over osteogenesis in human MSCs undergoing in-vitro aging. This outcome is consistent with the invivo observations that showed an increase in adipose tissue volume, but decreased bone formation, when MSCs senesce [54].

\section{Conclusions}

The current work presents a thorough investigation on variations in phenotype and differentiation capability of in-vitro aging human MSCs derived from bone marrow. We found that MSCs subjected to extensive in-vitro passage can experience morphological, phenotypic, and genetic changes. These properties are also modulated by the medium formula employed to expand the cell populations. While aged MSCs maintain a certain ability to differentiate toward the adipogenic lineage regardless of the expansion condition, their osteogenic potential is significantly impaired by senescence. For osteogenic induction, one must first consider MSCs at early passages, 

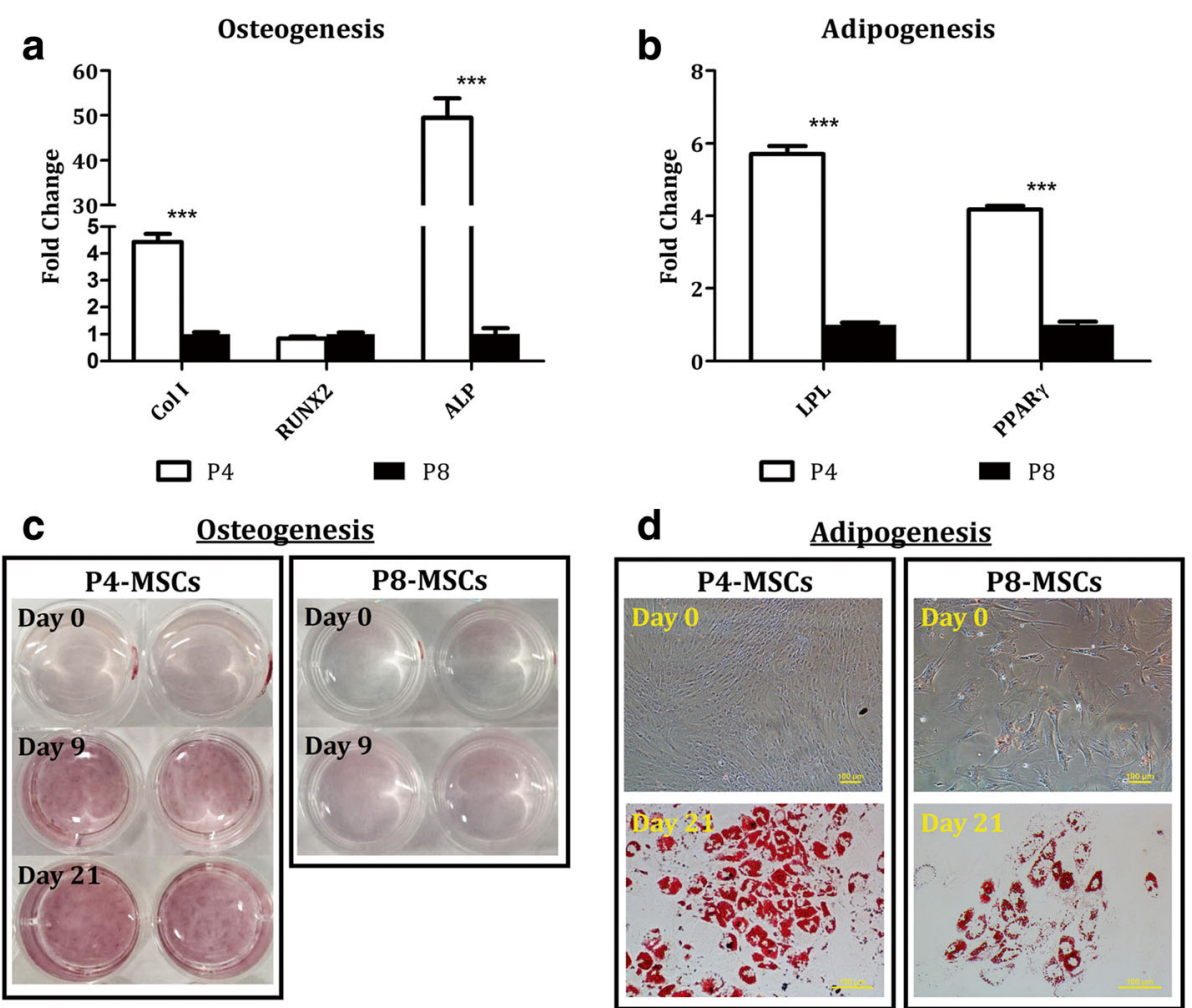

Fig. 9 Differentiation capacity of P4-MSCs versus P8-MSCs derived from the aMEM-based expansion condition. MSCs at P4 or P8 were cultivated with either osteogenic (a, $\mathbf{c}$ ) or adipogenic (b, d) differentiation media for up to 21 days. a Gene expression of osteogenic samples was assessed on day 9. b Gene expression of adipogenic samples was assessed on day 21. In qPCR, GAPDH was used as the reference gene, and the corresponding P8 samples were used as the control groups. $n=4 ;{ }^{* *} p<0.001$, versus the corresponding P8 groups. c Osteogenic cultures were stained histologically with Alizarin Red $\mathrm{S}$ and calcium is shown in a red color. $\mathbf{d}$ Adipogenic cultures were stained histologically with Oil Red $\mathrm{O}$ and lipids are shown in a red color. Scale bars $=100 \mu \mathrm{m}$. ALP, alkaline phosphatase; Col I, type I collagen; LPL lipoprotein lipase; MSC, mesenchymal stem cell; P, passage; PPARY, peroxisome proliferator-activated receptor $\gamma$; RUNX2, runt-related transcription factor 2

and use of the $\alpha M E M-b a s e d$ proliferation medium may yield longer osteogenesis and better quality. The extent of the observed changes attributed to in-vitro senescence, however, may be affected by several factors such as cell origin, donor age, and patient pathologic conditions which can yield MSCs with varied properties and functionalities and thus needs to be further evaluated. Collectively, this study provides insightful information for future basic science research and clinical applications leading to development of innovative MSC therapies for various diseases.

\section{Additional file}

Additional file 1: Figure S1. Relative telomere length of MSCS passaged in the DMEM-based (C) or aMEM-based (D) expansion medium. Relative telomere length was measured by SYBR Green QPCR amplification of telomere repeats and a single copy gene 36B4 [39]. Briefly, MSCs at different passage numbers were lysed overnight in a solution composed of $1 \%$ sodium dodecyl sulfate, $10 \mathrm{mM}$ Tris-hydrochloride, $1 \mathrm{mM}$ ethylenediaminetetraacetic acid, $100 \mathrm{mM}$ sodium chloride, and $300 \mathrm{mg} / \mathrm{mL}$ proteinase $\mathrm{K}$, followed by 2-h digestion with $\mathrm{Hinfl}$ and Rsal at $37^{\circ} \mathrm{C}$ to extract genomic DNA. Isolated DNA (35 ng/sample) was then mixed with SYBR Green PCR Master Mix and telomere or 36B4 primers. The final concentrations of the primers were as follows: telomere 1, 5'-GGTIITGAGGGTGAGGGTGAGGGTGAGGGTGAGGGT-3', 270 nM; telomere 2, 5'-TCCCGACTATCCCTATCCCTATCCCTATCCCTATC CCTA-3', 900 nM; 36B4u, 5'-CAGCAAGTGGGAAGGTGTAATCC-3', 300 nM; 36B4d, 5'-CCCATTCTATCATCAACGGGTACAA-3', 500 nM. The telomere and 36B4 PCRs were carried out in separate plates and the reactions consisted of an initial enzyme activation for $10 \mathrm{~min}$ at $95^{\circ} \mathrm{C}$, followed by 40 cycles of $15 \mathrm{~s}$ at $95^{\circ} \mathrm{C}$ and 2 min at $54{ }^{\circ} \mathrm{C}$ for telomere PCR or 40 cycles of $15 \mathrm{~s}$ at $95^{\circ} \mathrm{C}$ and $1 \mathrm{~min}$ at $58^{\circ} \mathrm{C}$ for $36 B 4$ PCR. Standard curves (A, B) generated from serial dilution of DNA (12.5 to $100 \mathrm{ng}$ ) extracted from the telomerase-positive K562 cell line were also included in PCRs and used to determine the quantities of telomere repeats (T) and 36B4 (S) from the corresponding Ct values of each sample. Relative telomere length was estimated as the T-to-S ratio. A decreasing trend in telomere length was observed over time in MSCs cultivated with either expansion medium. Specifically, the T-to-S ratio reduced from 1.53 at $P 3$ to 0.49 at $P 8$ in the DMEM group (C) and from 1.72 at P3 to 0.70 at P8 in the aMEM group (D). Numbers represent the mean values. $n=4 ;{ }^{*} p<0.05$, versus the corresponding P8-MSCs passaged under the same expansion condition. (PDF $711 \mathrm{~kb}$ )

\section{Abbreviations}

aMEM: Minimum essential medium alpha; ALP: Alkaline phosphatase; Col I: Type I collagen; CPDT: Cell population doubling time; Ct: Cycle threshold; DMEM: Dulbecco's modified Eagle's medium; ECM: Extracellular matrix; FBS: Fetal bovine serum; FGF-2: Basic fibroblast growth factor; GAPDH: Glyceraldehyde-3-phosphate dehydrogenase; HSC: Hematopoietic 
stem cell; LPL: Lipoprotein lipase; MSC: Mesenchymal stem cell; NCPD: Number of cell population doubling; P: Passage; PBS: Phosphatebuffered saline; PPARY: Peroxisome proliferator-activated receptor $\gamma$ qPCR: Real-time polymerase chain reaction; RUNX2: Runt-related transcription factor 2

\section{Acknowledgements}

The authors would like to thank Mr. Jeffery Walker from the Research Center in Minority Institutions (RCMI) at the City College of New York for his assistance with flow cytometry analysis.

\section{Funding}

This work was supported by the City College of New York Research Award (to GAB) and the Professional Staff Congress-City University of New York Research Award (grant number 60526-00 48 to YHKY).

\section{Availability of data and materials}

All data generated and/or analyzed during this study are available from the corresponding author on reasonable request.

\section{Authors' contributions}

YHKY conceived and performed this research, analyzed data, and wrote the manuscript. CRO, CWS, and TYC participated in data collection and analysis of the experiments. GAB reviewed all the data derived from this study and edited the manuscript. All the authors read and approved the final manuscript before submission.

\section{Consent for publication}

The authors consent to publication of all details and images for this manuscript.

\section{Competing interests}

The authors declare that they have no competing interests.

\section{Publisher's Note}

Springer Nature remains neutral with regard to jurisdictional claims in published maps and institutional affiliations.

\section{Author details \\ ${ }^{1}$ Department of Biomedical Engineering, The City University of New York - the City College, 160 Convent Avenue, Steinman 581, New York, New York 10031, USA. ²Department of Biomedical Engineering, The City University of New York - the City College, 160 Convent Avenue, Steinman 582, New York, New York 10031, USA. ${ }^{3}$ Department of Biomedical Engineering, The City University of New York - the City College, 160 Convent Avenue, Steinman 142, New York, New York 10031, USA.}

Received: 20 December 2017 Revised: 11 April 2018 Accepted: 13 April 2018 Published online: 11 May 2018

\section{References}

1. Chen FH, Rousche KT, Tuan RS. Technology insight: adult stem cells in cartilage regeneration and tissue engineering. Nat Clin Pract Rheum. 2006; 2(7):373-82

2. Yang Y-H, Lee AJ, Barabino GA. Coculture-driven mesenchymal stem celldifferentiated articular chondrocyte-like cells support neocartilage development. Stem Cells Transl Med. 2012;1(11):843-54.

3. Friedenstein AJ, Gorskaja JF, Kulagina NN. Fibroblast precursors in normal and irradiated mouse hematopoietic organs. Exp Hematol. 1976;4(5):267-74.

4. Diao H, Wang J, Shen C, Xia S, Guo T, Dong L, Zhang C, Chen J, Zhao J, Zhang J. Improved cartilage regeneration utilizing mesenchymal stem cells in TGF- $\beta 1$ gene-activated scaffolds. Tissue Eng Part A. 2009;15(9):2687-98.

5. Zucconi E, Vieira NM, Bueno DF, Secco M, Jazedje T, Ambrosio CE, PassosBueno MR, Miglino MA, Zatz M. Mesenchymal stem cells derived from canine umbilical cord vein-a novel source for cell therapy studies. Stem Cells Dev. 2010;19(3):395-402.

6. Yoshimura H, Muneta T, Nimura A, Yokoyama A, Koga H, Sekiya I. Comparison of rat mesenchymal stem cells derived from bone marrow, synovium, periosteum, adipose tissue, and muscle. Cell Tissue Res. 2007; 327(3):449-62.
7. Awad HA, Halvorsen YDC, Gimble JM, Guilak F. Effects of TGF- $\beta 1$ and dexamethasone on the growth and chondrogenic differentiation of adipose-derived stromal cells. Tissue Eng. 2003;9:1301-12.

8. Young HE, Mancini ML, Wright RP, Smith JC, Black AC, Reagan CR, Lucas PA. Mesenchymal stem cells reside within the connective tissues of many organs. Dev Dyn. 1995;202(2):137-44.

9. Sakaguchi Y, Sekiya I, Yagishita K, Muneta T. Comparison of human stem cells derived from various mesenchymal tissues: superiority of synovium as a cell source. Arthritis Rheum. 2005;52(8):2521-9.

10. Hu Y, Liao L, Wang Q, Ma L, Ma G, Jiang X, Zhao RC. Isolation and identification of mesenchymal stem cells from human fetal pancreas. J Lab Clin Med. 2003;141(5):342-9.

11. Kolf CM, Cho E, Tuan RS. Mesenchymal stromal cells: biology of adult mesenchymal stem cells: regulation of niche, self-renewal and differentiation. Arthritis Res Ther. 2007:9(1):204-13.

12. Hayflick L. Antecedents of cell aging research. Exp Gerontol. 1989;24(5):355-65.

13. Anklesaria P, Kase K, Glowacki J, Holland CA, Sakakeeny MA, Wright JA, FitzGerald TJ, Lee CY, Greenberger JS. Engraftment of a clonal bone marrow stromal cell line in vivo stimulates hematopoietic recovery from total body irradiation. PNAS. 1987;84(21):7681-5.

14. Koç ON, Gerson SL, Cooper BW, Dyhouse SM, Haynesworth SE, Caplan Al, Lazarus HM. Rapid hematopoietic recovery after coinfusion of autologousblood stem cells and culture-expanded marrow mesenchymal stem cells in advanced breast cancer patients receiving high-dose chemotherapy. J Clin Oncol. 2000;18(2):307.

15. Horwitz EM, Prockop DJ, Fitzpatrick LA, Koo WWK, Gordon PL, Neel M, Sussman M, Orchard P, Marx JC, Pyeritz RE, Brenner MK. Transplantability and therapeutic effects of bone marrow-derived mesenchymal cells in children with osteogenesis imperfecta. Nat Med. 1999;5(3):309-13.

16. Horwitz EM, Prockop DJ, Gordon PL, Koo WWK, Fitzpatrick LA, Neel MD, McCarville ME, Orchard PJ, Pyeritz RE, Brenner MK. Clinical responses to bone marrow transplantation in children with severe osteogenesis imperfecta. Blood. 2001;97(5):1227-31

17. Fukuda K, Sakamoto N, Narita T, Saitoh K, Kameda T, Iba H, Yasugi S. Application of efficient and specific gene transfer systems and organ culture techniques for the elucidation of mechanisms of epithelial-mesenchymal interaction in the developing gut. Develop Growth Differ. 2000;42(3):207-11.

18. Cherington V, Chiang GG, McGrath CA, Gaffney A, Galanopoulos T, Merrill W, Bizinkauskas CB, Hansen M, Sobolewski J, Levine PH, Greenberger JS, Hurwitz DR. Retroviral vector-modified bone marrow stromal cells secrete biologically active factor IX in vitro and transiently deliver therapeutic levels of human factor IX to the plasma of dogs after reinfusion. Hum Gene Ther. 1998;9(10):1397-407.

19. Friedenstein AJ, Latzinik NW, Grosheva AG, Gorskaya UF. Marrow microenvironment transfer by heterotopic transplantation of freshly isolated and cultured cells in porous sponges. Exp Hematol. 1982;10(2):217-27.

20. Wexler SA, Donaldson C, Denning-Kendall P, Rice C, Bradley B, Hows JM. Adult bone marrow is a rich source of human mesenchymal 'stem' cells but umbilical cord and mobilized adult blood are not. Br J Haematol. 2003; 121(2):368-74

21. Baxter MA, Wynn RF, Jowitt SN, Wraith JE, Fairbairn LJ, Bellantuono I. Study of telomere length reveals rapid aging of human marrow stromal cells following in vitro expansion. Stem Cells. 2004;22(5):675-82.

22. DiGirolamo CM, Stokes D, Colter D, Phinney DG, Class R, Prockop DJ. Propagation and senescence of human marrow stromal cells in culture: a simple colony-forming assay identifies samples with the greatest potential to propagate and differentiate. Br J Haematol. 1999;107(2):275-81.

23. Zhou S, Greenberger JS, Epperly MW, Goff JP, Adler C, LeBoff MS, Glowack J. Age-related intrinsic changes in human bone-marrow-derived mesenchymal stem cells and their differentiation to osteoblasts. Aging Cell. 2008;7(3):335-43.

24. Stolzing A, Jones E, McGonagle D, Scutt A. Age-related changes in human bone marrow-derived mesenchymal stem cells: consequences for cell therapies. Mech Ageing Dev. 2008;129(3):163-73.

25. Bruder SP, Jaiswal N, Haynesworth SE. Growth kinetics, self-renewal, and the osteogenic potential of purified human mesenchymal stem cells during extensive subcultivation and following cryopreservation. J Cell Biochem. 1997:64(2):278-94

26. Colter DC, Class R, DiGirolamo CM, Prockop DJ. Rapid expansion of recycling stem cells in cultures of plastic-adherent cells from human bone marrow. PNAS. 2000;97(7):3213-8. 
27. Banfi A, Muraglia A, Dozin B, Mastrogiacomo M, Cancedda R, Quarto R. Proliferation kinetics and differentiation potential of ex vivo expanded human bone marrow stromal cells: implications for their use in cell therapy. Exp Hematol. 2000;28(6):707-15.

28. Muraglia A, Cancedda R, Quarto R. Clonal mesenchymal progenitors from human bone marrow differentiate in vitro according to a hierarchical model. J Cell Sci. 2000;113(7):1161-6.

29. Bonab MM, Alimoghaddam K, Talebian F, Ghaffari SH, Ghavamzadeh A, Nikbin B. Aging of mesenchymal stem cell in vitro. BMC Cell Biol. 2006;7(1):14.

30. Alhadlaq A, Mao JJ. Mesenchymal stem cells: isolation and therapeutics. Stem Cells Dev. 2004;13(4):436-48.

31. Bahney CS, Hsu C-W, Yoo JU, West JL, Johnstone B. A bioresponsive hydrogel tuned to chondrogenesis of human mesenchymal stem cells. FASEB. 2011;25(5):1486-96.

32. Kyburz KA, Anseth KS. Three-dimensional hMSC motility within peptidefunctionalized PEG-based hydrogels of varying adhesivity and crosslinking density. Acta Biomater. 2013;9(5):6381-92.

33. Lin H, Lozito TP, Alexander PG, Gottardi R, Tuan RS. Stem cell-based microphysiological osteochondral system to model tissue response to interleukin-1ß. Mol Pharm. 2014;11(7):2203-12.

34. Sridhar BV, Brock JL, Silver JS, Leight JL, Randolph MA, Anseth KS. Development of a cellularly degradable PEG hydrogel to promote articular cartilage extracellular matrix deposition. Adv Healthc Mater. 2015;4(5):702-13.

35. Bian L, Zhai DY, Mauck RL, Burdick JA. Coculture of human mesenchymal stem cells and articular chondrocytes reduces hypertrophy and enhances functional properties of engineered cartilage. Tissue Eng Part A. 2011;17(7-8):1137-45.

36. Bian L, Guvendiren M, Mauck RL, Burdick JA. Hydrogels that mimic developmentally relevant matrix and $\mathrm{N}$-cadherin interactions enhance MSC chondrogenesis. PNAS. 2013;110(25):10117-22.

37. Bian L, Hou C, Tous E, Rai R, Mauck RL, Burdick JA. The influence of hyaluronic acid hydrogel crosslinking density and macromolecular diffusivity on human MSC chondrogenesis and hypertrophy. Biomaterials. 2013;34(2):413-21.

38. Livak KJ, Schmittgen TD. Analysis of relative gene expression data using real-time quantitative PCR and the $2^{-\Delta \Delta C t}$ method. Methods. 2001;25(4): 402-8.

39. Cawthon RM. Telomere measurement by quantitative PCR. Nucleic Acids Res. 2002;30(10):e47.

40. Guillot PV, Gotherstrom C, Chan J, Kurata H, Fisk NM. Human first-trimester fetal MSC express pluripotency markers and grow faster and have longer telomeres than adult MSC. Stem Cells. 2007:25(3):646-54

41. Pignolo RJ, Suda RK, McMillan EA, Shen J, Lee S-H, Choi Y, Wright AC, Johnson FB. Defects in telomere maintenance molecules impair osteoblast differentiation and promote osteoporosis. Aging Cell. 2008;7(1):23-31.

42. Liu L, DiGirolamo CM, Navarro PAAS, Blasco MA, Keefe DL. Telomerase deficiency impairs differentiation of mesenchymal stem cells. Exp Cell Res. 2004;294(1):1-8.

43. Shi S, Gronthos S, Chen S, Reddi A, Counter CM, Robey PG, Wang C-Y. Bone formation by human postnatal bone marrow stromal stem cells is enhanced by telomerase expression. Nat Biotechnol. 2002;20:587-91.

44. Simonsen JL, Rosada C, Serakinci N, Justesen J, Stenderup K, Rattan SIS, Jensen TG, Kassem M. Telomerase expression extends the proliferative lifespan and maintains the osteogenic potential of human bone marrow stromal cells. Nat Biotechnol. 2002;20:592-6.

45. Shibata KR, Aoyama T, Shima Y, Fukiage K, Otsuka S, Furu M, Kohno Y, Ito K, Fujibayashi S, Neo M, Nakayama T, Nakamura T, Toguchida J. Expression of the p16INK4A gene is associated closely with senescence of human mesenchymal stem cells and is potentially silenced by DNA methylation during in vitro expansion. Stem Cells. 2007;25(9):2371-82.

46. Blázquez-Prunera A, Díez JM, Gajardo R, Grancha S. Human mesenchymal stem cells maintain their phenotype, multipotentiality, and genetic stability when cultured using a defined xeno-free human plasma fraction. Stem Cell Res Ther. 2017:8(1):103.

47. Hayflick $L$. The limited in vitro lifetime of human diploid cell strains. Exp Cell Res. 1965:37(3):614-36.

48. Gronthos S, Zannettino ACW, Hay SJ, Shi S, Graves SE, Kortesidis A, Simmons PJ. Molecular and cellular characterisation of highly purified stromal stem cells derived from human bone marrow. J Cell Sci. 2003;116(9):1827-35.

49. Yang ZX, Han Z-B, Ji YR, Wang YW, Liang L, Chi Y, Yang SG, Li LN, Luo WF, Li JP, Chen DD, Du WJ, Cao XC, Zhuo GS, Wang T, Han ZC. CD106 identifies a subpopulation of mesenchymal stem cells with unique immunomodulatory properties. PLoS One. 2013;8(3):e59354.
50. Lu S, Ge M, Zheng Y, Li J, Feng X, Feng S, Huang J, Feng Y, Yang D, Shi J, Chen F, Han Z. CD106 is a novel mediator of bone marrow mesenchymal stem cells via NF-kB in the bone marrow failure of acquired aplastic anemia. Stem Cell Res Ther. 2017:8(1):178.

51. Sacchetti B, Funari A, Michienzi S, Di Cesare S, Piersanti S, Saggio I, Tagliafico E, Ferrari S, Robey PG, Riminucci M, Bianco P. Self-renewing osteoprogenitors in bone marrow sinusoids can organize a hematopoietic microenvironment. Cell. 2007;131(2):324-36.

52. Granéli C, Thorfve A, Ruetschi U, Brisby H, Thomsen P, Lindahl A, Karlsson C. Novel markers of osteogenic and adipogenic differentiation of human bone marrow stromal cells identified using a quantitative proteomics approach. Stem Cell Res. 2014;12(1):153-65.

53. Castrén E, Sillat T, Oja S, Noro A, Laitinen A, Konttinen YT, Lehenkari P, Hukkanen M, Korhonen M. Osteogenic differentiation of mesenchymal stromal cells in two-dimensional and three-dimensional cultures without animal serum. Stem Cell Res Ther. 2015;6(1):167.

54. Justesen J, Stenderup K, Ebbesen EN, Mosekilde L, Steiniche T, Kassem M. Adipocyte tissue volume in bone marrow is increased with aging and in patients with osteoporosis. Biogerontology. 2001;2(3):165-71.

\section{Ready to submit your research? Choose BMC and benefit from:}

- fast, convenient online submission

- thorough peer review by experienced researchers in your field

- rapid publication on acceptance

- support for research data, including large and complex data types

- gold Open Access which fosters wider collaboration and increased citations

- maximum visibility for your research: over $100 \mathrm{M}$ website views per year

At BMC, research is always in progress.

Learn more biomedcentral.com/submissions 